\title{
Quality management systems selection using FAHP and mixed integer programming
}

\author{
Majid Nojavan $^{\mathrm{a}}$, Amir abbas Shojaie ${ }^{\mathrm{a}^{*}}$ and Mohammad Eftekhari ${ }^{\mathrm{a}}$
}

${ }^{a}$ School of Industrial Engineering, Islamic Azad University, South Tehran Branch, Tehran, Iran

\begin{tabular}{|c|c|}
\hline AR T I C L E I N F O & A B S T R A C T \\
\hline $\begin{array}{l}\text { Article history: } \\
\text { Received February } 1,2011 \\
\text { Received in Revised form } \\
\text { April, } 25,2011 \\
\text { Accepted } 28 \text { April } 2011 \\
\text { Available online } \\
28 \text { April 2011 } \\
\text { Keywords: }\end{array}$ & $\begin{array}{l}\text { In current paper, an organized and quantitative approach is proposed for selection of quality } \\
\text { management systems. The proposed model of this paper first uses fuzzy analytic hierarchical } \\
\text { process to rank different quality management systems. Since there are normally various } \\
\text { constraints associated with the selection of quality management, we propose a } 0-1 \\
\text { programming for selecting an optimal mix of quality management systems. We also use the } \\
\text { proposed model of this paper for a real-world case study of research center in aerial industries } \\
\text { and the results are discussed. }\end{array}$ \\
\hline
\end{tabular}

\section{Introduction}

Quality management systems are considered important tools in the direction of continuous improvement and two issues of policy making for selection of appropriate system and their implementation methods. There are qualitative and quantitative approaches for selection of quality management systems. There are three approaches in the qualitative approach including general approach, gap analysis and synthetic approach. In the general approach, implementation of quality management systems is conducted from simple to difficult in which emphasis is on informing and standardizing before implementation. Gap analysis approach depends on quo status analysis and strategic objectives of the firm, which is a disorganized method and its implementation depends on the executer. Finally, in the synthetic approach, a set of systems are suggested for implementation.

In quantitative approaches quality management systems are selected based on firm criteria and demands and using experts' opinions. This method is more precise compared with qualitative methods due to its measurability (Giuliano et al., 1998). Tsai et al. (2009) presented a hybrid approach for selection of managerial systems based on sustainable development within small firms. In this hybrid approach, selection of managerial systems is based on four factors including financial,

\footnotetext{
* Corresponding author. Tel. +9821-88830826

E-mail addresses: Amir@ashojaie.com (A. Shojaee) 
growth and learning, shareholders and customers, and internal processes aspects. After determining initial alternatives of managerial systems, they identified the quantities of all quadruple criteria in the balanced evaluation card. In the next stage, using weights network analysis process, all decision making criteria are determined and finally by indentifying limitations and using 0-1 linear programming method, the optimum mix for selection of managerial systems is presented. However, in their method, several indices of balanced evaluation card are not identified. Further, the problem was solved by a definite approach. Thawesaengskulthai (2008) presented a method to determinate the quality management and consistent improvement. In the selection of quality management systems, first he presents the quality management systems selection model in the form of a hierarchical model and he determined criteria and sub-criteria for selecting quality management systems based on deductive and inductive approaches and weights of criteria and sub-criteria is identified using experts' consensus mechanism. Finally, the relative significance of alternatives is determined using questionnaires and experts' opinions and the quality management systems were ranked by simple weight averaging from values determined by experts. In Thawesaengskulthai's method, facilitating assumptions were used for determining weights and calculating agents are simple. In addition to this, organizational limitations were not included in selecting quality management systems. In the proposed method of this article, fuzzy AHP method was used for ranking quality management systems, then using the obtained results and organizational limitations, a 0-1 linear programming was proposed for selecting the best optimal mix for aerial industries research center. In this paper, we present an empirical method based on his approach to select the most appropriate quality applications. The organization of this article is as follows. We first present the proposed method in section 2 and the results from applying the proposed method in the selection of quality management systems in aerial industries research center are examined in section 3. Finally, concluding remarks are given in the last section to summarize the contribution of the paper.

\section{Proposed method description}

The proposed method of this paper has the following steps,

\subsection{Experts selection}

In order to answer the research questions, two groups of experts are used. Answering the questions about criteria and sub-criteria is performed using 5 administrative (executive) experts teams and consensus mechanism. Answers to questions about the relative significance of alternatives are collected through five experts from quality management systems who are holders of official evaluation certificate for quality management systems.

\subsection{Determination of quality management systems and screening them}

We use ISO quality management system, six sigma, comprehensive quality management, European foundation quality management, Malcum Baldrige foundation quality management, business process reengineering, lean production system and benchmarking as management systems usually used for our study.

First in these systems, quality management systems are screened according to experts' opinion. In this respect, since there is no tangible sample of comprehensive quality management in the aerial industries research center, this system is removed from the list of initial alternatives. In addition, Malcom Baldrige model is omitted due to its lack of prevalence in industrial community of Iran. Six sigma is also omitted due to its production-oriented approach because this research center is considered a research organization. However, lean production system was not omitted in spite of its production- oriented nature because this center emphasis was on lean thought.

\subsection{Ranking quality management systems using fuzzy hierarchical analysis process}

Analysis Hierarchical process is one of multi-attribute decision making methods used for decisionmaking and selecting one alternative from among multiple decision alternatives with regard to criteria determined by decision maker or criteria identified for him. This technique examines complex 
problems according to their mutual effects, makes them simple and begins to solve them. Fuzzy analytical hierarchy process (FAHP) and fuzzy multiple criteria decision making (FMCDM) are widely used for criteria evaluation and alternative selections. Hsieh et al. (2004) indicated the advantages and sustainability results in using this method in connection with qualitative and quantitative criteria. In order to determine the relative significance of quality management systems alternatives and their ranking, FAHP developed by Chan Chen et al. (2009) was used. This method includes modeling steps, determination of pairwise comparisons, weights calculation, determination of final weights of alternatives and finalizing fuzzy weights. The proposed method of this paper has the following steps,

Step 1. modeling

In this step, the purpose and problem of decision-making are established hierarchically from decision elements which are connected to each other. In order to create a hierarchical structure for selecting quality management systems it is necessary to identify selection criteria and sub-criteria. For this purpose, regarding the research conducted by Thawesaenngskulthai (2008), four basic indices are used: proportionate to strategy, results, proportionate to organization, and being update for which a sub-index is considered. Note that indices and sub-indices are examined by experts and their application is acknowledged for selection of quality management systems in organization. The hierarchical structure used in this model is indicated in Fig.1.

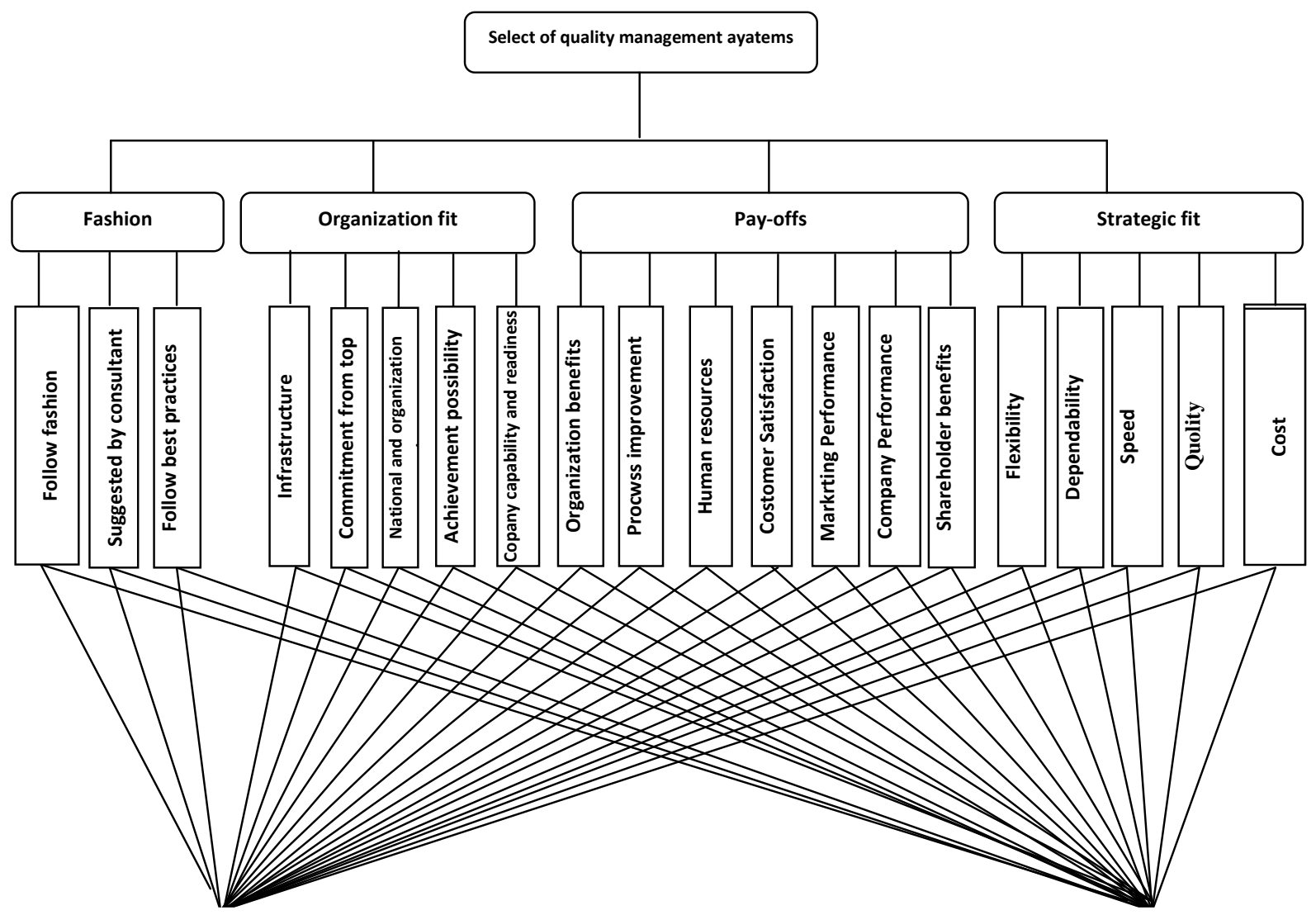

Fig. 1.The hierarchical structure for quality management systems selection and alternatives assessment

Step 2: Determination of preferred perceptions in the form of pair-wise comparison matrix In this step, using pair-wise comparisons, each of the related factors with higher levels is compared and scored relative to each level. Generating pair-wise comparisons among all elements/criteria/subcriteria and alternatives in dimensions of the hierarchical system with assignment of linguistic terms to pair-wise comparisons by determining that which of the two criteria with two elements is more 
important. A linguistic variable is used to express the importance of each attribute which are shown in Table 1.

\section{Table 1}

Linguistic terms used for the proposed study of this paper

\begin{tabular}{lcl}
\hline Linguistic scales & Fuzzy number & Scale of fuzzy number \\
\hline Equally important( Eq) & $\tilde{1}$ & $(1,1,3)$ \\
Weakly important( Wk) & $\tilde{3}$ & $(1,3,5)$ \\
Essentially important( Es) & $\tilde{5}$ & $(3,5,7)$ \\
Very strongly important( Vs) & $\tilde{7}$ & $(5,7,9)$ \\
Absolutely important( As) & $\tilde{9}$ & $(7,9,9)$ \\
\hline
\end{tabular}

Note that the information of Table 1 are adopted from the work by Chiou and Tzeng(2001) and fuzzy number scale in Mon et al.(1994).

Linguistic variables are transformed to fuzzy numbers using one scale. In the linguistic variables used for factors comparison, these variables are transformed to triangular fuzzy numbers. A triangular fuzzy number is indicated by an ordered triplet $(1, \mathrm{~m}, \mathrm{n})$ and its membership degree function is as follow,

$\mu_{\widetilde{\mathrm{A}}}(\mathrm{x})=\left\{\begin{array}{cl}\frac{X-L}{M-L} & L \leq x \leq M \\ \frac{U-X}{U-M} & M \leq x \leq U \\ 0 & \text { otherwise }\end{array}\right.$

where $L$ and $U$ represent the lower and the upper bounds, $\breve{A}$ and $M$ are mean value, respectively and we use triangular fuzzy operations. Inconsistency rate for each pair wise comparison matrix, which indicatives the degree of conflicts in pairwise perceptions of decision-makers is also calculated and compared with the minimum acceptable level, experimentally suggested as 0.1 . In cases where inconsistency proportion is higher than this value, after calculating the geometrical mean of experts' opinions using EC software, the overall consistency and the inconsistent alternative are identified and with respect to the proposed priorities of the software with reconsidering experts' opinions, some of the values are modified and weights calculations are performed.

\section{Step 3: Relative weights calculations}

In order to calculate criteria and sub-criteria weights compared to each other, Bakley method (1985) is used. In this method, for calculating weights in each pair-wise comparison matrix, the geometrical mean of each line was used as follow:

$\tilde{r}_{i}=\left(\tilde{a}_{i 1} \otimes \tilde{a}_{i 2} \otimes \tilde{a}_{i 3} \otimes . . \quad \widetilde{a_{i n}}\right)^{\frac{1}{n}}$

$\widetilde{w}_{i}=\tilde{r}_{i} \otimes\left(\tilde{r}_{1} \oplus \ldots \oplus \tilde{r}_{n}\right)^{-1}$

where $\breve{a}_{i j}$ is the degree of fuzzy significance of the element of line 1 relative to the element of column $\mathrm{j}$ in pair-wise comparison matrix, $\breve{\mathrm{r}}_{\mathrm{i}}$ is the geometrical mean of line $\mathrm{i}$ element, and $\hat{\mathrm{w}}_{\mathrm{i}}$ is weight of line $i$ element. Note that $\breve{r}_{i}$ and $\hat{w}_{i}$ are not triangular fuzzy number but are estimated by triangular fuzzy numbers.

Step 4: Integrating the relative weights and determining the final rank of quality management systems In order to determine the final weights of a quality management system, the relative weights present in each direction related to that system are multiplied by each other and the obtained values for each direction are added. Finally, the obtained weights were normalized. 
Step 5: Finalizing the rank of quality management systems

Since the obtained ranks for quality management systems are considered as triangular fuzzy numbers, it is essential to remove their fuzzy state. In this research a method called deffuzification is used for defuzzifying (Opricovic \& Tzeng, 2003; Hsieh et al.2004).

$d(u, 0)=\frac{(U-L)+(M-L)}{3}+\mathrm{L}$

2.4. Designing a mathematical model for optimal selection of quality management systems:

The main purpose in this stage is to select the optimal mix of quality management systems where terms and limitations of firm are considered. In other words, the firm allocates a limited budget to the quality issue, which is not practically increasable. Another limiting issue is that only limited hours assigned to implementation of quality management systems. Finally, the last limiting issue is the necessary hours for executing these systems. Eq. (5) represents the mathematical formulation of the proposed model.

$$
\begin{aligned}
\max Z= & c_{1} x_{1}+c_{2} x_{2}+c_{3} x_{3}+c_{4} x_{4}+c_{5} x_{5} \\
& a_{11} x_{1}+a_{12} x_{2}+a_{13} x_{3}+a_{14} x_{4}+a_{15} x_{5} \leq b_{1} \\
& a_{21} x_{1}+a_{22} x_{2}+a_{23} x_{3}+a_{24} x_{4}+a_{25} x_{5} \leq b_{2} \\
& a_{31} x_{1}+a_{32} x_{2}+a_{33} x_{3}+a_{34} x_{4}+a_{35} x_{5} \leq b_{3} x_{1}, \ldots, x_{5} \in(0,1) .
\end{aligned}
$$

In Eq. (5) $c_{1}$ to $c_{5}$ are the relative weights of alternatives $x_{1}$ to $x_{5}$, respectively. The weights are obtained using the proposed fuzzy AHP model. The first constraint is associated with the amount of expenditures needed to spend on quality management system, which includes consultation, education, certificate receiving, and cultural works. The second constraint is for time limitation that we have and finally the third constraint specifies the amount of time to execute the quality management.

\section{Data collection and analysis}

The proposed approach was applied for selecting quality management systems in the research center of aerial industries.

\section{1. data collection}

In order to answer the research questions, two groups of experts were used and questionnaire were distributed among the experts.

\subsection{Calculating the weights of primary and secondary criteria}

In order to calculate criteria and sub-criteria weights, first the results from questionnaires are quantified, then, the geometrical mean of the results was calculated, finally primary and secondary criteria weights were determined using Expert Choice software. Pair wise comparison matrix of primary criteria compared to the objective is presented in Table 2.

\section{Table 2}

Pair-wise comparison matrix of primary criteria

\begin{tabular}{lllll}
\hline selection & Strategic fit & Pay-offs & Organization fit & Fashion \\
\hline Strategic fit & 1.00 & 2.37 & 0.46 & 7.14 \\
Pay-offs & 1.00 & 1.00 & 1.93 & 6.87 \\
Organization fit & 1.00 & 1.00 & 1.00 & 5.83 \\
Fashion & 1.00 & 1.00 & 1.00 & 1.00 \\
\hline
\end{tabular}

\subsection{Calculating the inconsistency rate}

After receiving experts' opinions and performing the necessary calculations, inconsistency values were calculated and modified. An example is presented in Table 3. Calculations by software indicated 
that inconsistency value related to the geometrical mean of pairwise comparison matrix is $0.18 \%$ which is higher than the acceptable value. The highest inconsistencies are respectively related to the alternatives shown in table 3.

Table 3

Inconsistency rate calculate based on software proposal

\begin{tabular}{llllllll}
\hline $\begin{array}{l}\text { Expert } \\
\text { opinion }\end{array}$ & $\begin{array}{l}\text { Propose of } \\
\text { software }\end{array}$ & $\begin{array}{l}\text { Six } \\
\text { alternative }\end{array}$ & $\begin{array}{l}\text { Five } \\
\text { alternative }\end{array}$ & $\begin{array}{l}\text { Four } \\
\text { alternative }\end{array}$ & $\begin{array}{l}\text { Three } \\
\text { alternative }\end{array}$ & $\begin{array}{l}\text { Two } \\
\text { alternative }\end{array}$ & $\begin{array}{l}\text { One } \\
\text { alternative }\end{array}$ \\
\hline 2.14 & 2.14 & 6.68 & 7.14 & 5.83 & 1.93 & 2.37 & 0.46 \\
\hline
\end{tabular}

With regard to software suggestions, we referred to experts' opinions and changing the first alternative, from $0.46 \%$ to $7.14 \%$ was acknowledged by experts. Therefore, inconsistency value was reduced to 0.05 which is located in an acceptable boundary. As such, in similar cases after calculating geometrical mean of experts' opinions, inconsistency values were obtained. Calculations related to geometrical mean of relative weights of criteria and sub-criteria were conducted after removing inconsistency.

\subsection{Calculating the alternative weights using FAHP}

a) Generating pair wise comparison matrix: in order to generate a pair wise comparison matrix, similar questionnaires were given to five experts in quality management systems and they were asked to determine the relative significance of each of these systems based on linguistic variables according to sub-criteria. The output of this step for each alternative is five pair wise comparison matrices completed by five experts.

b) Using fuzzy geometrical mean, five experts' opinions were merged.

$$
\tilde{a}_{i j}=\left(\tilde{a}^{1}{ }_{i j} \otimes \tilde{a}^{2}{ }_{i j} \otimes \tilde{a}^{3}{ }_{i j} \otimes \tilde{a}^{4}{ }_{i j} \otimes \tilde{a}^{5}{ }_{i j}\right)^{1 / 5}
$$

c) After merging experts' opinions, using Bakley method, fuzzy geometrical mean and fuzzy weights were merged. For example

$$
\begin{aligned}
& \widetilde{w}_{1}=\tilde{\mathrm{r}}_{1} \otimes\left(\tilde{\mathrm{r}}_{1} \oplus \tilde{\mathrm{r}}_{2} \oplus \tilde{\mathrm{r}}_{3} \oplus \tilde{\mathrm{r}}_{4} \oplus \tilde{\mathrm{r}}_{5}\right)^{-1} \\
& \widetilde{w}_{1}=\tilde{\mathrm{r}}_{1} \otimes\left(\tilde{\mathrm{r}}_{1} \oplus \tilde{\mathrm{r}}_{2} \oplus \tilde{\mathrm{r}}_{3} \oplus \tilde{\mathrm{r}}_{4} \oplus \tilde{\mathrm{r}}_{5}\right)^{-1}
\end{aligned}
$$

Other values related to $r$, i.e, $r_{2}, r_{3}, r_{4}, r_{5}$ and other values related to $w$ were calculated.

d) in the last step, criteria weights were transformed to fuzzy numbers and deffuzified. For example

$$
\mathrm{BNP}_{w_{1}}=\frac{\left[\left(\mathrm{U}_{\mathrm{w}_{1}}-\mathrm{l}_{\mathrm{w}_{1}}\right)+\left(\mathrm{M}_{\mathrm{w}_{1}}-\mathrm{l}_{\mathrm{w}_{1}}\right)\right]}{3}+\mathrm{L}_{\mathrm{w}_{1}}
$$

Some of these results are given in Table 4 .

\section{Table 4}

The mean values of the fuzzy numbers

\begin{tabular}{lllllllllllllllll}
\hline & ISO & \multicolumn{4}{c}{ EFQM } & \multicolumn{4}{c}{ BPR } & \multicolumn{4}{c}{ Bench } & \multicolumn{3}{c}{ Lean } \\
cost & $\mathrm{a}$ & $\mathrm{b}$ & $\mathrm{c}$ & $\mathrm{a}$ & $\mathrm{b}$ & $\mathrm{c}$ & $\mathrm{a}$ & $\mathrm{b}$ & $\mathrm{c}$ & $\mathrm{a}$ & $\mathrm{b}$ & $\mathrm{c}$ & $\mathrm{a}$ & $\mathrm{b}$ & $\mathrm{c}$ & $\mathrm{BNP}$ \\
\hline ISO & 1 & 1 & 1 & 0.57 & 0.9 & 1.6 & 0.34 & 0.43 & 1.12 & 0.93 & 1.26 & 2.4 & 1.4 & 1.63 & 2.71 & 0.17 \\
EFQM & 0.63 & 1.11 & 1.75 & 1 & 1 & 1 & 0.8 & 1.16 & 2.29 & 1.93 & 2.95 & 4 & 1.53 & 2.53 & 3.55 & 0.26 \\
BPR & 0.89 & 2.33 & 2.94 & 0.44 & 0.86 & 1.25 & 1 & 1 & 1 & 1.33 & 2.66 & 4.36 & 1.72 & 2.04 & 4.43 & 0.26 \\
Bench & 0.42 & 0.79 & 1.08 & 0.25 & 0.34 & 0.52 & 4.36 & 2.66 & 1.33 & 1 & 1 & 1 & 0.9 & 1.38 & 3.16 & 0.19 \\
Lean & 0.37 & 0.61 & 0.71 & 3.55 & 2.53 & 1.53 & 4.43 & 2.04 & 1.72 & 3.16 & 1.38 & 0.9 & 1 & 1 & 1 & 0.20 \\
\hline
\end{tabular}


Table 5

FAHP computations

\begin{tabular}{|c|c|c|c|c|c|c|c|}
\hline & & & Lean & Bench & BPR & EFQM & ISO \\
\hline \multirow{5}{*}{ Strategic fit 0.463} & cost & 0.061 & 0.224 & 0.227 & 0.157 & 0.309 & 0.232 \\
\hline & quality & 0.232 & 0.164 & 0.164 & 0.245 & 0.373 & 0.191 \\
\hline & speed & 0.109 & 0.238 & 0.207 & 0.246 & 0.185 & 0.157 \\
\hline & Dependability & 0.47 & 0.222 & 0.227 & 0.157 & 0.309 & 0.232 \\
\hline & Flexibility & 0.126 & 0.216 & 0.161 & 0.324 & 0.276 & 0.132 \\
\hline \multirow{7}{*}{ Pay-offs 0.291} & Shareholder benefit & 0.122 & 0.179 & 0.250 & 0.186 & 0.294 & 0.278 \\
\hline & Company performance & 0.148 & 0.200 & 0.268 & 0.200 & 0.292 & 0.237 \\
\hline & $\begin{array}{l}\text { Marketing } \\
\text { performance }\end{array}$ & 0.121 & 0.176 & 0.267 & 0.126 & 0.433 & 0.028 \\
\hline & Customer satisfaction & 0.228 & 0.158 & 0.194 & 0.115 & 0.487 & 0.266 \\
\hline & Human resources & 0.135 & 0.205 & 0.212 & 0.138 & 0.368 & 0.204 \\
\hline & Process improvement & 0.068 & 0.178 & 0.099 & 0.197 & 0.512 & 0.126 \\
\hline & Organization benefits & 0.178 & 0.177 & 0.158 & 0.215 & 0.625 & 0.154 \\
\hline \multirow{5}{*}{ Organization fit 0.201} & Capability & 0.125 & 0.156 & 0.265 & 0.144 & 0.368 & 0.338 \\
\hline & $\begin{array}{l}\text { Achievement } \\
\text { possibility }\end{array}$ & 0.072 & 0.229 & 0.184 & 0.144 & 0.328 & 0.130 \\
\hline & $\begin{array}{l}\text { National } \\
\text { organization }\end{array}$ & 0.126 & 0.194 & 0.270 & 0.128 & 0.370 & 0.267 \\
\hline & Top level commitment & 0.606 & 0.170 & 0.307 & 0.130 & 0.326 & 0.35 \\
\hline & infrastructure & 0.073 & 0.177 & 0.405 & 0.171 & 0.223 & 0.388 \\
\hline \multirow{3}{*}{ Fashion 0.12} & Follow best practice & 0.621 & 0.243 & 0.237 & 0.176 & 0.268 & 0.2 \\
\hline & $\begin{array}{l}\text { Suggested } \\
\text { consultant }\end{array}$ & 0.187 & 0.243 & 0.237 & 0.176 & 0.268 & 0.2 \\
\hline & Follow fashion & 0.192 & 0.243 & 0.237 & 0.176 & 0.268 & 0.2 \\
\hline & & & 0.192 & 0.22 & 0.176 & 0.342 & 0.23 \\
\hline
\end{tabular}

\subsection{The final weights of alternatives}

After calculating the criteria and sub-criteria and alternatives weights, final results are presented in Table 5.

3.6. The proposed model for selecting quality management systems in aerial industries research center

Table 5 summarizes the necessary information needed to solve the mixed integer programming given in Eq. (5). The first row of this table presents the normalized weights of five alternatives, the other rows show the constraints' coefficients, and the last column presents the right hand side (RHS) of the constraints.

\section{Table 5}

The final weights of different alternatives

\begin{tabular}{|c|c|c|c|c|c|c|}
\hline Alternative & LEAN & Benchmarking & BPR & EFQM & ISO & RHS \\
\hline Weight & 0.165 & 0.19 & 0.151 & 0.294 & 0.2 & - \\
\hline $\begin{array}{l}\text { Consulting, Certification and culturing } \\
\text { fee }\end{array}$ & 50 & 300 & 500 & 30 & 40 & 400 \\
\hline Training hours & 60 & 80 & 30 & 20 & 35 & 200 \\
\hline Labor hours & 100 & 3000 & 600 & 100 & 300 & 4200 \\
\hline
\end{tabular}

Solving the 0-1 mathematical programming problem given in Eq. (5) yields the optimal solution where three alternatives of Benchmarking, ISO and EFQM are chosen to be implemented. 


\section{Conclusions}

In this paper, we have presented an integrated method to select appropriate quality improvement systems. The proposed model of this paper presented fuzzy analytical hierarchy process to rand different quality improvement systems and a mathematical programming technique was used to choose optimal combinations of various techniques subject to some consulting, certification and culturing fee as well as training and labor hours limitations. The method was also implemented for a real-world case study of aerial industry and the results were discussed.

\section{References}

Buckley, J. J., (1985). Fuzzy hierarchical analysis, Fuzzy Sets and Systems, 17 (3), 233-247.

Chen,V. Y. C., Tzeng, H. P., Yang, C. H., Liou, J. J. H., Tzeng, G. H., Yang, L. S. (2011). Fuzzy MCDM approach for selecting the best environment-watershed plan. Applied Soft Computing, 11(1), 265-275.

Chiou, H. K., Tzeng, G. H. (2001). Fuzzy hierarchical evaluation with grey relation model of green engineering for industry. International Journal Fuzzy Systems, 3(3), 466-475.

Hsieh,T.Y., Lu, S.T.,\& Tzeng, G.H. (2004). Fuzzy MCDM approach for planning and design tenders selection in public office buildings. International Journal of Project Management, 22(7), 573-584.

Mon,DL. \& Cheng,ch.,(1994).,Evaluation weapon system using fuzzy analytic hierarchy process on entropy weight. Fuzy Sets and Systems, 62(2), 127-134.

Noci, G., \& Toletti, G. (1998).A decision Support Systems for the Selection of quality-based programmes in small firms. Management Decision, 36(7), 473-486.

Opricovic, S. \&Tzeng, G.H. (2002). Multi criteria planning of post-earthquake sustainable reconstruction. Computer-Aided Civil and Infrastructure Engineering, 17(3), 211-220.

Thawesaengskulthai, N., \& Tannock, J. (2008). Fashion setting in quality management and continuous improvement. International Studies of Management \& Organization, 38(2), 5-24.

Tsai,W-H \& Chou, W-C., (2009). Selecting management systems for sustainable development in SMEs: A novel hybrid model based on DEMATEL, ANP, and ZOGP. Expert systems with applications, 36(2),1444-1458.

Van Laarhoven, P. J. M., \& Pedrycz, W. (1983). A fuzzy extension of Saaty's priority theory, Fuzzy Sets and systems,11(3), 199-227.

Wu, H. Y. \& Tzeng, G. H. \& Chen,Y-C. (2009). A fuzzy MCDM approach for evaluating banking performance base on balanced Scorecard. Expert systems with applications, 36(6), 10135-10147. 